\title{
ПНЕВМАТИКА В ВОДНЫХ ТЕХНОЛОГИЯХ - ОПТИМИЗАЦИЯ ТЕХНОЛОГИЧЕСКИХ ПРОЦЕССОВ
}

\author{
Рыженко Е.С. ${ }^{1}$, Трипольская А.С. ${ }^{1}$ \\ ${ }^{1}$ ДП «Фесто»
}

Copyright (C) 2014 by author and the journal "Automation technological and business - processes". This work is licensed under the Creative Commons Attribution International License (CC BY). http://creativecommons.org/licenses/by/4.0/
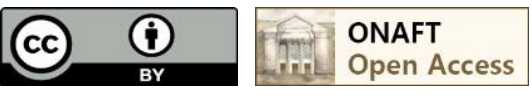

Пневматика в водных технологиях - оптимизация технологических процессов

Со времен индустриализации технические решения претерпели существенные изменения, благодаря которым практически все отрасли промышленности получили возможность производить больше единиц товара, быстрее и эффективней. В процессах автоматизации использование пневматики стало очевидным двигателем прогресса, найдя множество применений в современном мире технологий. Особый бум в последнее время отмечается в автоматизации технологий водоподготовки, в частности при очистке воды, зарождая тесное переплетение пневматики и водных технологий. История становления и принципы действия, преимущества и недостатки, а главное - применение пневматики в ключе быстроразвивающейся и перспективной отрасли водоснабжения - факты, прогнозы, тенденции, а также мнения экспертов.

\section{Пневматика - дыхание автоматизации}

Со страниц истории мира вырисовывается узнаваемый образ: человек дует на трут и разжигает огонь. Это один из самых простых и в то же время потрясающих примеров пневматического устройства - форма жизни с ее естественным «компрессором». К примеру, человеческие легкие способны перерабатывать 100 л/мин или 6 м/час, производя давление 0,02-0,08 бар.

Основоположный принцип действия пневматики - воздух высокого давления, который производится с помощью компрессоров. Ключ ее успеха в том, что энергия сжатого воздуха способна приводить механизмы в движения, при этом гарантируя последним долгий срок службы. Сжатый воздух выгоден, поскольку он требует меньших затрат в обслуживании и простые условия хранения. Другими словами, пневматика укрощает сжатый воздух, применяя его для эффективной работы на благо человечества.

Несмотря на то, что сжатый воздух использовался еще со времен античности, пневматика в промышленных секторах начала активно применятся только с начала 19-го столетия, первоначально в очистных целях посредством обдува. Со временем сжатый воздух стал использоваться на производстве для реализации автоматических циклов.

За последние десять лет пневматика обрела новый импульс, вздохнула по-новому, во многом благодаря тесному взаимодействию с электроникой, пройдя путь от миниатюризации модулей до встроенных промышленных компьютеров. Сегодня, объединив пневматику и электронику буквально в одном корпусе, пневмооборудование прельщает разработчиков и конструкторов всего мира простотой управления и высоким быстродействием.

Это стало новым этапом восхождения пневматики на Олимп промышленной автоматизации, который в дальнейшем позволил не только автоматизировать системы, но и наделить их особым интеллектом. Благодаря современным коммуникационным интерфейсам, таким как Ethernet, программируемые контроллеры образовали вместе с пневмоостровами компактные модули, воплотив концепцию действительно интеллектуальной системы, способной общаться, регулировать и взаимодействовать. Новые технологии, интегрированные в пневмокомпоненты и системы, вывели промышленную автоматизацию на базе сжатого воздуха на принципиально новый уровень. К примеру, благодаря сети Ethernet, скорость передачи информации достигает 10 Гбит/сек. Тем не менее, остается очевидным, что вершина инновационного процесса по-прежнему впереди: вполне вероятно, что будущее - за программируемыми ПК и децентрализованными системами. 
Воздушные реалии - прогрессивное использование пневматики в водных технология

Отечественная водоочистная инфраструктура и системы водоподготовки на промышленных предприятиях нуждаются в перезагрузке, частью которой является не только модернизация оборудования, но и существенная оптимизация технологических процессов. В зависимости от области применения, эксперты рекомендуют решения на базе пневматического оборудования: от элементарных позиционеров до платформы автоматизации.

Рассмотрим возможные решения для управления в замкнутых системах на водоочистных станциях. Один из самых простых вариантов, исходя из коэффициента цена/функциональность - это внешний позиционер, к примеру, CMSX со встроенным микроконтроллером, который отображает текущее положение запорного клапана. При этом клапан легко управляется с помощью аналогового сигнала, в то время как контроллер постоянно сопоставляет заранее заданное значение с фактическим положением четвертьоборотного привода. Это является оптимальным решением для замкнутых систем управления, так как позволяет сразу обнаружить неисправности и принять необходимые меры по их устранению.

Однако на станциях водоочистки дополнительные внешние устройства могут стать причиной дополнительных проблем: коррозия, быстрый износ движущихся частей, риски повреждения во время монтажа или эксплуатации. Альтернатива - это интеграция функции управления в сам привод. В этом случае необходимые компоненты - цилиндр, датчик перемещения, блок клапанов и позиционер - надежно интегрированы в единый корпус. Конкретным примером является линейный привод DFPI, который к тому же отличается компактностью и прочностью.

Таким образом, в секторе очистки воды и сточных вод, учитывая агрессивные среды, пневмопривод имеет заслуженную репутацию лидера благодаря простой конструкции и управлению, а также меньшей требуемой выделенной мощности в сравнении с электроприводами. К примеру, выделенная мощность для арматуры с электроприводом будет в 7-10 раз больше, чем требуемая выделенная мощность для компрессора (пневмоприводов). Поэтому проекты с использованием пневмоприводов зачастую позволяют серьезно сэкономить на проектировании, строительстве подстанций и разводке силовых электрических сетей. Кроме того, для данного сегмента рынка характерна потребность в наружной установке: требование, под которое идеально подходит пневмопривод. Дополнительное преимущество - простота хранения сжатого воздуха: в случае сбоя электропитания, есть возможность выполнить необходимые операции за счет накопленных энергетических резервов. В целом, как показывает практика, пневматические цепи управления позволяют снизить эксплуатационные расходы и оптимизировать процессы на предприятии, поэтому зачастую перестроить управление непрерывными процессами, используя пневматику, экономически выгодно.

Платформа автоматизации XXI века - принцип «один за всех и все за одного»

Децентрализованное управление процессами на производстве открывает широкие возможности: от простой экономии времени и денежных ресурсов до внедрения усовершенствованных высокотехнологичных решений. В отрасли водоснабжения данная проблематика, а именно переход к децентрализации систем управления, особенно сокрушительна. К примеру, местные станции водоподготовки насчитывают от 2-х и более фильтров с неподвижным слоем, тогда как более крупные станции в мегаполисах - до 48-ми. Как правило, управление одним фильтром осуществляется с помощью 5-8 запорных клапанов, три из которых установлены в замкнутых системах управления, остальные работают в открытом/закрытом режиме. В этом случае долгосрочное управление вручную будет чрезвычайно дорогостоящим по сравнению с возможной альтернативой переходом к децентрализации.

С помощью новой концепции автоматизации - децентрализованной и гибкой, объединяющей как пневмо-, так и электроприводы - можно осуществлять локальные процессы управления, находясь в центральной диспетчерской. Рассмотрим пневматическое управление запорными клапанами с использованием платформы CPX с пневмоостровом серии MPA и контролером CPX-CEC, программируемым в среде CoDeSys 2.3, без дополнительной установки позиционеров. Принцип действия очень простой - платформа обрабатывает электрические сигналы датчиков, осуществляя непосредственно управление пневмоприводами с помощью $5 / 3$ распределителей на пневмоострове. Отметим, что пропускная способность клапанов, интегрированных в систему, составляет от 200 до 4500 л/мин.

Модульная система управления СРХ устанавливается совместно с панелью оператора в шкаф управления, тогда как каждый фильтр с неподвижным слоем подключается к отдельному шкафу. При этом в системе предусмотрена возможность удаленного изменения параметров управления непосредственно в шкафу управления, а панель оператора позволяет управлять системой в ручном режиме в аварийном состоянии или в случае сбоя питания. В дополнение, система осуществляет функции диагностики и контроля состояния. Однако, наиболее выдающиеся особенности терминала СРХ - функциональная интеграция и высокая 
модульность, что гарантирует установку дополнительных модулей при необходимости, к примеру, модулей для мониторинга температуры, регулирования или измерения давления.

В конечном итоге система децентрализованного управления на базе пневмоострова СРХ-МРА обеспечивает ощутимый рост эффективности (от $10 \%$ до 60\%), оптимизирует время цикла на $30 \%$, позволяет сократить потребление сжатого воздуха до $50 \%$, а также минимизирует время простоя оборудования и экономит рабочее пространство. Преимущества данной платформы многочисленны, но одно очевидно: для производства, в особенности для отрасли водоснабжения, пневматика с электрической системой управления - это бесхитростная и практичная технология, которая характеризируется необычайной легкостью установки и управления, быстродействием и точностью выполняемых задач.

Перспективы пневматики в сочетании с мембранными технологиями

Последнее время процесс очистки питьевой воды и сточных вод в промышленной и коммунальной сферах с использованием мембранных технологий вызывает сильный научный резонанс. Перспективы данной технологии - злободневная тема для многих исследовательских центров, компаний и других учреждений. На повестке дня - эффективность мембранных технологий на базе пневмооборудования при управлении процессами.

В области водоочистки все чаще микро-, ультра- и нанофильтрация заменяют существующие методы, такие как песчаная фильтрация, поскольку мембраны способны фильтровать частицы разных размеров. Наряду с данной тенденцией, мембранные биореакторы (МБР) становятся привлекательной альтернативой первичной и вторичной обработке. Какую же роль в мембранных технологиях играет пневматика?

Дело в том, что для очистки мембран необходимы регулярные циклы обратного потока, которые осуществляются через мембранную поверхность. В этой области применения пневмоприводы по функциональности значительно превосходят электроприводы. Причиной этому - регулярные циклы переключения, которые даже при среднем сроке эксплуатации превышают 1 млн. Пневмопривод, в сравнении с другим оборудованием (клапанами или фитингами) зарекомендовал себя не только как надежное, но и выносливое устройство даже в чрезвычайно суровых окружающих условиях.

Пневматические компоненты устойчивы к практически любым промышленным условиям - влажности, жаре или холоду - благодаря коррозионно-стойкому исполнению. Диапазон температур может колебаться от $20{ }^{\circ} \mathrm{C}$ до $+80{ }^{\circ} \mathrm{C}$, а в специальном исполнении из нержавеющей стали они способны выдержать предельно низкие и высокие показатели: от $-40{ }^{\circ} \mathrm{C}$ до $+120{ }^{\circ} \mathrm{C}$.

Стоит отметить, что мобильные системы фильтрации пользуются популярностью в области водоочистки, выигрывая за счет следующих характеристик: компактность, портативность, возможность стандартизации; эффективность фильтрации (устранение даже самых мелких микроорганизмов, вирусов и микробов), а также высокий уровень автоматизации благодаря встроенному пневмооборудованию.

Энергоэффективные решения для водных технологий

Наряду с очисткой сточных вод, важную роль играет эффективное управление инфраструктурой системы в целом: электро- и теплоснабжением с целью уменьшения потерь воды в ходе производственных процессов и экономии электроэнергии. Диапазон возможных технически решений предлагает различные способы оптимизации - к примеру, повышение уровня автоматизации в таких областях, как дистанционный мониторинг в реальном времени. Это позволит значительно упростить процессы мониторинга, а значит контролировать и избегать, к примеру, утечек воды. Актуальными остаются решения по автоматизации процессов, способствующие сокращению объемов потребляемой станциями энергии. Таким образом, оптимизированный технологический процесс позволяет получить больший объем воды при меньшем расходе энергии.

Эксперт по водоочистке Водоканала в Санкт-Петербурге делится своим опытом: «В Санкт-Петербурге для питания электроприводов требовалась максимально затратная мощность в размере 90 кВт. Простой заменой электроприводов на 120 пневмоприводов, мы сумели дополнительно сэкономить не менее 65 кВт электроэнергии». Отметим, что ежедневно Водоканал обеспечивает 4,8 миллиона человек питьевой водой в объеме 1,9 миллиона куб. м. Таким образом, благодаря внедрению пневмоавтоматики Водоканал смог значительно сэкономить свои энергоресурсы.

Секрет сбережения энергии состоит в том, что пневмоприводу требуется энергия только на короткий промежуток времени, в течение которого происходит повышение давления. Сам процесс удержания может полностью проходить без подачи сжатого воздуха, исключая затраты на энергоресурсы. 
Однако не стоит забывать, что энергоэффективность автоматизированного оборудования зависит от его промышленного применения. «Именно этот аспект должен быть определен до выбора привода электрического, пневматического или сочетания обоих», - утверждает Роланд Фольк, консультант по вопросам энергоэффективности в компании Festo.

К таким выводам пришли специалисты немецкого холдинга Festo, разработав более 100 проектов по автоматизации для городских станций подготовки питьевой воды и более 200 проектов по очистке сточных вод на промышленных предприятиях, а также множество проектов в других сферах. Комплексную разработку и внедрение технических решений компания реализует благодаря широкому диапазону пневмо- и электрооборудования - от приводов и отдельных компонентов до готовых к монтажу систем, а также инжиниринговым решениям специалистов Festo.

Вот один из ярких примеров комплексных решений от Festo. Для водоочистных станций в Моссел-Бей возле Кейптауна компания Festo предложила решение по автоматизации процесса очистки воды - новую систему управления расходом сырой воды и автоматизированную систему фильтрации. По итогам проекта пропускная способность системы увеличилась на 15000 куб. м воды в сутки.

\section{Выводы}

Невозможно вывести определенную формулу перевеса пневматики над электромеханикой или наоборот. И главное, в этом нет весомой необходимости: пневматика это отнюдь не ультимативное решение. Технические возможности пневмоавтоматики имеют как преимущества, так и недостатки, поэтому первоначальной точкой отсчета должно стать определение конкретной области применения. Однако автоматизация процессов в области водоснабжения на базе пневмооборудования приносит дивиденды, и во многих случаях - это эффективное решение. Простота установки и эксплуатации, надежность и выносливость оборудования, устойчивость к неблагоприятным условиям среды, простота и безопасность хранения воздушного топлива и высокая технологичность - выдвигают пневматику на передовую линию автоматизации процессов.

\section{НОВ НОВТИ АВТОМАТИЗАЦИИ}

Журнал Автоматизация технологических и бизнес - процессов был принят к участию целым рядом авторитетных реферативных баз данных и систем индексирования.

Так, на сегодняшний день наш журнал представлен в следующих системах:

1. С 01.07.2014 года согласно заключенному договору с Ассоциацией академических издателей CrossRef и Publishers International Linking Association, Inc (PILA) - каждой статье опубликованной в нашем журнале будет присвоен уникальный DOI (digital object identifier) номер;

2. Журнал реферируется в базе данных Национальной библиотеки Украины им. В.И. Вернадского

3. Журнал реферируется в базе данных Ассоциации «УРАН»;

4. Журнал индексируется в Universal Impact Factor $\{\mathrm{UIF}\}$;

5. Журнал индексируется в Directory of Research Journal Indexing (DRJI);

6. Журнал индексируется в Open Academic Journal Indexing (OAJI);

7. Журнал индексируется в Directory of Open Access Journals (DOAJ);

8. Журнал является участником совместного с UNESCO и ISSN Международного проекта ROAD (Directory of Open Access scholarly Resources);

9. Журнал индексируется в Citefactor; 